DOI https://doi.org/10.30525/978-9934-26-075-9-27

\title{
SIGNS OF ABDOMINAL SEPSIS IN PATIENTS WITH GENERALIZED PERITONITIS
}

\author{
Fuss Yu. O. \\ Candidate of Medical Sciences, surgeon, \\ Central Regional Hospital in Pustomyty \\ Pustomyty, Lviv region, Ukraine \\ Voloboyeva A. O. \\ Anesthesiologist \\ Communal Municipal Clinical Hospital 8 \\ Lviv, Ukraine \\ Polovyj V. P. \\ Doctor of Medical Sciences, Professor, \\ Head of the Department of General Surgery \\ Bukovinian State Medical University \\ Chernivtsi, Ukraine
}

Despite the noticeable progress in the surgical treatment of acute surgical diseases of the abdominal organs, the incidence of secondary generalizated purulent peritonitis (SGPP) remains high, and the mortality rate for it varies from 25 to $41.5 \%$ [1,2]. Recently, great importance has been attached to the abdominal complement syndrome and its components - intra-abdominal and intraluminal intestinal hypertension, which are predictors of multiple organ dysfunction and the development of generalized abdominal infection (AI) in generalized peritonitis $[3,4,5]$. The pathogenetic approach to SGPP therapy involves the prevention and minimization of organ damage in ischemic reperfusion syndrome. However, there are not enough studies on the relationship between abdominal compartment syndrome and the severity of ischemic reperfusion syndrome and the development of AI $[6,7]$.

The aim: study the increase in ischemic reperfusion syndrome and intraabdominal hypertension syndrome as processes that cause the occurrence of abdominal sepsis in patients with SGPP.

Materials and methods. The study included 157 patients in whom the course of SGPP was studied. The average age of the patients was $54.8 \pm 5.8$ years. Retrospective the assessment of the severity of the course of infection in patients with SGPP was carried out in accordance with the basic 108 
positions of "Sepsis-3", namely: 1) qSOFA scale; 2) organ dysfunction (MOD); 3) septic shock (sepsis + MOD) against the background of persistent hypotension, requiring the introduction of vasopressors to maintain blood pressure cf. $\geq 65 \mathrm{~mm} \mathrm{Hg}$, lactate level $>0.249 \mathrm{mg} / 1$ (an indicator of the severity of the course of infection), against the background of adequate fluid therapy. The assessment of the patient's condition and the variability of the course of intra-abdominal infection was carried out according to the Mannheim Peritonitis Index (MIP) and the APACHE II scale. The severity of MOD and the effectiveness of its treatment in the interval were assessed by the integral indicators of the SOFA scale. As a marker of the development of ischemic reperfusion syndrome and $\mathrm{AI}$, we used the indices of the concentration of lactate (LCT) in the peripheral blood plasma.

Results. In the structure of SGPP etiology, acute intestinal obstructtion prevailed - 47 (29.9\%) patients and perforated duodenal ulcer $38(24.2 \%)$ patients. Colon perforations, ventral hernias with entrapment of internal organs, and acute appendicitis were the causes of SGPP in 17 (10.9\%), $15(9.6 \%)$ and $12(7.6 \%)$ cases, respectively. More rare causes of SGPP were pancreatic necrosis - $10(6.4 \%)$, abdominal trauma $-9(5.7 \%)$ and perforation of the small intestine in $9(5.7 \%)$ cases.

The distribution of patients in the groups is presented as follows: the first group of $38(24.2 \%)$ patients with grade 1 intra-abdominal hypertension (IAH) and mild ischemic reperfusion syndrome (IRS), the second group 45 (28.7\%) patients with grade 2 IAH and moderate IRS, the third group 52 (33.1\%) patients with grade $3 \mathrm{IAH}$ and

severe IRS, the fourth group with grade 4 IAH and extremely severe IRS - 22 (14\%) patients.

With the increase IAH, visceral circulatory disorders progressed, which is associated with the subsequent restoration of perfusion of internal organs and severe metabolic changes, from mild to extremely severe IRS. In the second group of patients, the qSOFA scale indices indicated the presence of a generalized infectious process, but this did not mean the prospect of ascertaining sepsis after surgery (Table 1).

The indices of the integral scales APACHE II, SOFA, MIP reflected a clear relationship between the severity of the course of intra-abdominal infection and the severity of IAH. Abdominal complement syndrome was pronounced in cases of small bowel obstruction, colonic perforations, pancreatic necrosis. 
Table 1

Integral Scale Indicators and Plasma Lactate Concentration depending on the degree of intra-abdominal hypertension before surgery

\begin{tabular}{|c|c|c|c|c|}
\hline Indicators & \multicolumn{4}{|c|}{ Degree of intra-abdominal hypertension (WSACS) (n = 157) } \\
\hline & I (n=38) & II (n=45) & $\begin{array}{c}\text { III (n=52) } \\
\text { SEPSIS }\end{array}$ & $\begin{array}{c}\text { IV (n=22) } \\
\text { Septic shock }\end{array}$ \\
\hline $\begin{array}{c}\text { APACHE II } \\
\text { (scores) }\end{array}$ & $12,8 \pm 0,4$ & $13,6 \pm 0,4$ & $16,3 \pm 0,4^{*}$ & $18,9 \pm 0,6^{*}$ \\
\hline MIP (scores) & $9,7 \pm 0,3$ & $21,1 \pm 0,3$ & $25,2 \pm 0,8^{*}$ & $26,4 \pm 0,7^{*}$ \\
\hline $\begin{array}{c}\text { SOFA } \\
\text { (scores) }\end{array}$ & $3,2 \pm 0,1$ & $3,2 \pm 0,1$ & $3,8 \pm 0,2^{*}$ & $4,3 \pm 0,1^{*}$ \\
\hline $\begin{array}{c}\text { Intra- } \\
\text { abdominal } \\
\text { pressure } \\
\text { (mm Hg) }\end{array}$ & $11,2 \pm 0,4$ & $18,6 \pm 0,6$ & $27,6 \pm 1,4^{*}$ & $37,9 \pm 1,2^{*}$ \\
\hline $\begin{array}{c}\text { Plasma lactate } \\
(m g / l)\end{array}$ & $0,246 \pm 0,05$ & $0,249 \pm 0,04$ & $0,363 \pm 0,06^{*}$ & $0,423 \pm 0,07^{*}$ \\
\hline
\end{tabular}

Plasma LCT values tended to increase, parallel to the IAH progression. In the first two degrees of IAH, the complex of decompression procedures had a polyvalent structure aimed at curbing the progression of mild to moderate IRS.

In the first and second groups of patients before and after surgery, the differences in blood plasma LCT levels are insignificant. The immediate postoperative period was accompanied by an increase in IAH up to $30 \%$ of the initial, which was explained by inflammatory changes in the parietal and visceral peritoneum, intestinal dysfunction and VCG. Subsequently, the IAH indices, by the sixth day after the operation, evenly decreased to normal. The peak increase in plasma LCT concentration, up to a maximum of $0.36 \pm 0.03 \mathrm{mg} / 1$, corresponded to the second day after surgery and was accompanied by manifestations of endotoxicosis. An integrated assessment of the severity of the patients' condition showed a maximum of $14.7 \pm 0.4$ points and $3.4 \pm 0.2$ points on the APACHE II scale and the SOFA scale, respectively. In the first two groups of SGPP patients, there was no direct indication of the presence of ACS and MOD, but according to the APACHE II and SOFA scales, the likelihood of developing AI in the future became quite real.

In the third and fourth groups of patients, operations were completed with procedures aimed at decompression of the abdominal cavity and intestines. In 29 cases, nasointestinal intubation was performed during surgery and / or reoperation, and in 45 patients, temporary closure of the surgical wound with skin sutures was performed. 
Conclusion. In patients with secondary widespread purulent peritonitis and abdominal complement syndrome, as intra-abdominal hypertension decreases, manifestations of the ischemia-reperfusion syndrome appear. The severity of reperfusion injuries depends on the severity of intra-abdominal hypertension and intraluminal intestinal hypertension, the timing of their existence, the method and rate of de-compression of the abdominal cavity and intestines.

The relationship between an increase in the level of peripheral blood plasma lactate and the type of decompression of the abdominal cavity has been established. A rapid decrease in intra-abdominal pressure, when using nasointestinal intubation, leads to a pronounced increase in the peak level of peripheral blood lactate and is accompanied by the appearance of signs of multiple organ dysfunction and septic shock in all cases.

With the most pronounced intra-abdominal hypertension and intraluminal intestinal hypertension, conservative measures, supplemented by decompression laparostomy between program sanitization of the abdominal cavity or emergency relaparotomy, contributed to a smooth decompression of the abdominal cavity within 2-3 days after the operation and were accompanied by a more gentle plateau and decrease in the level of intra-abdominal plasma pressure . Such an approach to the complex treatment of extremely severe ischemia-reperfusion syndrome can reduce mortality in abdominal sepsis and septic shock to $15.6 \%$.

\section{References:}

1. Firoozamand E, Fairman N, Sklar J, Waxman K. Intravenous interleukin-6 levels predict need for laparotomy in patients with bowel obstruction. Am Surg 2001 Dec;67(12):1145-1149.

2. Lange $H$, Jackel $R$. Usefulness of plasma lactate concentrations in the diagnosis of acute abdominal disease. Eur J Surg 1994 Jun-Jul;160 (6-7):381-384.

3. Murray MJ, Gonze MD, Nowak LR, Cobb CF. Serum D(-)-lactate levels as an aid to diagnosing acute intestinal ischemia. Ann J Surg 1994 Jun;167(6):575-578.

4. Kurimoto Y, Kawaharada N, Ito T, Morikawa M, Higami T, Asai Y. Experimental evaluation of lactate concentration following mesenteric ischemia. Surg Today 2008;38(10):926-930.

5. Smith SM, Eng HK, Buccini F. Use of D lactic acid measurement in the diagnosis of bacterial infections. J Infect Dis 1986 Oct;154(4):658-664.

6. Perlmutter DH, Boyle JT, Campos JM, Egler JM, Watkins JB. D-lactic acidosis in children: an unusual metabolic complication of small bowel resection. J Pediatr 1983 Feb;102(2):234-238. 
7. Mahmut B, Ahmet B, Ahmet K, Akçay F, Selçuk SA. Serum D(-)lactate and nitric oxide (NO) levels in acute intestinal ischemia. Tr J Med Sci 1999;29:37-40.

DOI https://doi.org/10.30525/978-9934-26-075-9-28

\title{
FEATURES OF ECHO-CARDIOGRAPHIC INDICATORS \\ OF THE LEFT VENTRICLE IN ELDERLY WOMEN PATIENTS \\ WITH STABLE ANGINES WITH AND WITHOUT \\ COMORBIDBOID TYPE II DIABETES MELLITUS
}

\author{
Khapitska O. P. \\ Candidate of Medical Sciences, \\ Associate Professor at the Department of Internal medicine № 3, \\ National Pirogov Memorial Medical University \\ Sarafyniuk L. A. \\ Doctor of Biological Sciences, Professor, \\ Head of the Department of Physical training, \\ National Pirogov Memorial Medical University \\ Merculova D. $O$. \\ Assistant at the Department of Propedeutics \\ of Pediatric Diseases with Patient Care \\ National Pirogov Memorial Medical University \\ Shinkaruk-Dykovytska M. M. \\ Doctor of Medical Sciences, Professor, \\ Head of the Therapeutic Dentistry Department, \\ National Pirogov Memorial Medical University \\ Vinnytsya, Ukraine
}

Relevance: Coronary heart disease (CHD) is one of the most serious diseases of the cardiovascular system, with a high risk of cardiovascular disorders and even death [1, p. 193]. Ischemic heart disease is a leading cause of disability and mortality in economically developed countries [2, p. 92] and, as a result, remains one of the most pressing medical and socio-economic problems of modern society [3, p. 938]. Scientists have become increasingly 